\title{
Glutamine decreases intestinal mucosal injury in a rat model of intestinal ischemia-reperfusion by downregulating HMGB1 and inflammatory cytokine expression
}

\author{
XIAOLIANG SHU ${ }^{1}$, JIAN ZHANG ${ }^{2}$, QINGXIU WANG $^{2}$, ZENGGUANG XU $^{3}$ and TINGTING YU ${ }^{2}$ \\ ${ }^{1}$ Department of Nutrition, Jinshan Hospital, Fudan University School of Medicine, Shanghai 201508; \\ ${ }^{2}$ Department of Anesthesiology and ${ }^{3}$ Research Center for Translational Medicine, East Hospital, \\ Tongji University School of Medicine, Shanghai 200120, P.R. China
}

Received December 30, 2015; Accepted June 17, 2016

DOI: $10.3892 / e t m .2016 .3468$

\begin{abstract}
Intestinal ischemia-reperfusion (IR) is a common clinical pathophysiological process that is common in severe trauma, major surgery, and in post-resuscitation. Glutamine (Gln) reduces intestinal IR injury, however, its mechanism of action remains to be determined. High mobility group box 1 (HMGB1) protein, nuclear factor- $\kappa \mathrm{B}$ (NF- $\mathrm{kB}$ ), tumor necrosis factor- $\alpha$ (TNF- $\alpha$ ), and interleukin-1 (IL-1) are mediators involved in the pathophysiology of intestinal IR injury. The aim of the present study was to investigate the effects of Gln on the intestinal mucosa of HMGB1 expression following IR to determine whether Gln relieved intestinal IR injury in the intestinal mucosal barrier. Forty-eight Sprague-Dawley rats were included in the present study. A model of intestinal ischemia-reperfusion injury was established by clamping the superior mesenteric artery of the rats to cause ischemia, followed by restoring blood flow. The animals were randomly divided into the control $(\mathrm{n}=24)$ and the Gln $(n=24)$ groups for the experiments. The two groups of rats were given enteral nutrition with equal heat, nitrogen (heat $125.4 \mathrm{~kJ} / \mathrm{kg} / \mathrm{day}$, nitrogen $0.2 \mathrm{~g} / \mathrm{kg} /$ day). The Gln group of rats was fed with enteral nutrition plus $3 \% \mathrm{Gln}$, while the control rats were fed with enteral nutrition plus $3 \%$ soybean protein. After 7 days, the HMGB1 and plasma levels of NF- $\kappa B$, TNF- $\alpha$, IL-1, Gln, D-lactic acid and diamine oxidase (DAO) were observed. The changes in the morphology of intestinal mucosa were observed using electron microscopy. The plasma levels of TNF- $\alpha$, IL-1, D-lactic acid and DAO, and the level of HMGB1, NF- $\mathrm{KB}$, TNF- $\alpha$ and IL-1 in intestinal mucosa were significantly higher after IR $(\mathrm{p}<0.05)$, while the plasma level
\end{abstract}

Correspondence to: Dr Zengguang Xu, Research Center for Translational Medicine, East Hospital, Tongji University School of Medicine, 150 Jimo Road, Shanghai 200120, P.R. China

E-mail: xuzg1998@126.com

Key words: glutamine, ischemia-reperfusion, high mobility group box 1 , intestinal mucosa, permeability of Gln was lower in the two groups. In the control group, the plasma level of IL-1, TNF- $\alpha$, DAO and D-lactic acid, and that of HMGB1, NF- $\kappa$ B, TNF- $\alpha$, and IL-1 in intestinal mucosa were significantly higher, while the plasma level of Gln was lower than that prior to modeling on the 3rd and 7th days of the experiment. In the Gln group, the plasma level of IL-1, TNF- $\alpha$, DAO and D-lactic acid, and that of HMGB1, NF- $\kappa$ B, IL-1, and TNF- $\alpha$ in intestinal mucosa were significantly higher $(\mathrm{p}<0.05)$ compared to the control on the 3rd and 7th days of the experiment. By contrast, after the 7th day, the plasma level of IL-1, TNF- $\alpha$, DAO and D-lactic acid, and the level of HMGB1, $\mathrm{NF}-\kappa \mathrm{B}, \mathrm{IL}-1, \mathrm{TNF}-\alpha$ in intestinal mucosa were significantly lower in the Gln group, while the plasma level of Gln was significantly higher than those in control group and after IR on the 7th day of the experiment. Additionally, the structure of villi and recess was damaged, villi was sparse and short, and considerable inflammatory cell influx embellished the lamina propria, lymphangiectasia, and edema after IR. On the 7th day, compared to after IR, the intestinal villi and recess structure of the controls was significantly restored in the Gln group. In conclusion, Gln repaired the intestinal mucosal injury in IR by reducing the expression of HMGB1 and inflammatory cytokines, and reducing the permeability of the intestinal mucosa.

\section{Introduction}

During intestinal ischemia-reperfusion (IR), mucosal tissue damage is associated with cytokine release, increase in intestinal mucosal permeability, translocation of endotoxins and intestinal microflora. These can lead to multiple organ dysfunction syndrome (MODS) $(1,2)$. Inflammatory response of lower intestinal mucosa is a crucial factor defining mucosal damage after IR caused by major surgery or severe trauma (3).

Glutamine (Gln) is a conditionally essential amino acid with a variety of biological functions. It is the key energy substrate for intestinal epithelial cells and lymphocytes. It is required to maintain proper mucosal barrier function as it promotes cell differentiation and proliferation (4-6). To the best of our knowledge, few studies have focused on the effects of Gln on inflammatory cytokine production in intestinal mucosa after IR. 
In the present study, we established an animal model of intestinal IR injury and tested the effects of Gln on mucosal function as well as the high mobility group box 1 (HMGB1), tumor necrosis factor- $\alpha$ (TNF- $\alpha)$, interleukin-1 (IL-1). The results showed that Gln repaired the intestinal mucosal injury in IR by reducing the expression of HMGB1 and inflammatory cytokines, and reduce the permeability of intestinal mucosa.

\section{Materials and methods}

\section{Animals}

Animal model of IR. Forty-eight healthy male Sprague-Dawley rats were obtained from the Experimental Animal Center of Tongji University (Shanghai, China). The animals had an average weight of $150 \pm 12 \mathrm{~g}$. After feeding for 3 days, the animals were anesthesized and fixed on a wooden board, and a ventral midline incision (3-4 cm long) into the abdomen was performed. The mesenteric arteries were identified and isolated, the initial part of the upper mesentery artery was clamped with a non-damagebulldog clamp (Jinzhong Co., Shanghai, China) for $35 \mathrm{~min}$, prior to the clamp being loosened to re-perfuse for $2 \mathrm{~h}$. This established a small intestinal IR injury.

Animal groups. Animals were randomly divided into the control and Gln groups ( $n=24$ per group). The rats were fed separately in a clean animal house with stainless steel cage. The control group rats were fed vegan chow (Nutricia) supplemented with $3 \%$ soy protein, whereas the Gln group animals were fed vegan chow (Nutriciacompany, Paris, France) supplemented with $3 \%$ Gln. The enteral nutrition of the two groups had the following calorie and nitrogen supply: calorie $125.4 \mathrm{~kJ} / \mathrm{kg} /$ day and nitrogen $0.2 \mathrm{~g} / \mathrm{kg} /$ day. Enteral nutrition supplemented with $3 \%$ Gln and $3 \%$ soybean protein was given once. Prior to feeding enteral nutrition to rats, daily disposable lavage, change of food intake and body weight were measured.

Prior and after induction of IR injury (days 3 and 7 of the experiment), 6 rats were selected to obtain $5 \mathrm{ml}$ of arterial blood from the femoral artery. Blood was centrifuged for $10 \mathrm{~min}$ at $2,000 \mathrm{x}$ g to collect serum, and then stored at $-80^{\circ} \mathrm{C}$. In addition, small intestine $10 \mathrm{~cm}$ away from the ileocecal intestinal tissue was also obtained to evaluate the levels of HMGB1, TNF- $\alpha$ and IL-1, and for pathological analysis.

HMGB1 expression. HMGB1 expression was assessed using western blot analysis, as previously described (7). The homogenates of intestinal mucosa were prepared and supernatants were obtained and separated with SDS-PAGE. The primary antibody, anti-HMGB1 antibody (catalog no.: sc-191583; Santa Cruz Biotechnology, Inc., Santa Cruz, CA, USA) and secondary antibody (Santa Cruz Biotechnology, CA, USA; catalog no.:sc-395763) were subsequently applied. The gel image was captured and bands were analyzed with quantity one image analysis software (Bio-Rad, Berkeley, CA, USA).

TNF- $\alpha$ and IL-1 expression. A $2 \mathrm{~cm}$ specimen of small intestine proximal jejunum was obtained. The specimen was rinsed with normal saline and 200-300 mg of intestinal mucosa were scraped off the jejunum. The tissue homogenate were diluted with nine volumes of normal saline. The specimen was centrifuged $(800 \mathrm{x} \mathrm{g}$ for $10 \mathrm{~min})$ and the supernatant was obtained.
The concentrations of TNF- $\alpha$ and IL-1 were quantified with respective ELISAs (R\&D Systems, Inc., Minneapolis, MN, USA). The results were expressed as pg cytokine/g wet weight.

Plasma Gln TNF- $\alpha$, IL-1, diamine oxidase (DAO) and $D$-lactic acid. TNF- $\alpha$ and IL-1 were quantified by respective ELISAs (R\&D Systems, Inc.). The concentration of plasma D-lactic acid was also calculated by ELISA (Sigma, St. Louis, MO, USA) whereas the concentration of DAO was quantified spectrophotometrically (Hitachi 7600 automatic biochemical analyzer; Hitachi, Tokyo, Japan). Gln concentration was quantified by HPLC (7) (Waters, Milford, MA, USA).

Morphological changes. A 2-cm specimen of the proximal jejunum was obtained. After paraffin embedding, tissue slices were prepared and stained with hematoxylin and eosin. The slides were viewed under magnification (x100), electron microscopy observation of small intestinal villus and crypt structure organization allowed the assessment of morphological changes.

Statistical analysis. SPSS 13.0 statististical software (SPSS, Inc., Chicago, IL, USA) was used to analyze the data. Quantitative data were presented as mean \pm SD and analyzed by the paired t-test. Qualitative data were analyzed by the Chi-square test. $\mathrm{P}<0.05$ indicated statistical significance.

\section{Results}

Expression of HMGB1 in intestinal mucosa. Compared with basal values, the expression of HMGB1 intestinal mucosa was significantly $(\mathrm{p}<0.05)$ increased immediately after, and on days 3 and 7 after IR (Table I). Animals treated with Gln showed a significantly faster recovery of this parameter on day 7 after IR (Table I).

Expression of nuclear factor- $\kappa B(N F-\kappa B)$ in intestinal mucosa. Compared with basal values, the percentage of $\mathrm{NF}-\kappa \mathrm{B}$-positive cells was markedly upregulated immediately after, and on days 3 and 7 after IR injury (Table II). Similar to HMGB1 expression, the animals treated with Gln showed a significantly ( $p<0.05$ vs. control group; Table II) faster decrease in the number of NF- $\kappa \mathrm{B}$-positive cells on day 7.

Levels of IL-1 and TNF- $\alpha$ in plasma and intestinal mucosa. Compared with before modeling, two groups after modeling of blood plasma and intestinal mucosal IL-1 and TNF- $\alpha$ level increased significantly $(\mathrm{p}<0.05)$. On the $3 \mathrm{rd}$ and 7 th day of the experiment, the control group of intestinal mucosa and serum IL-1 and TNF- $\alpha$ level was significantly higher than the former $(\mathrm{p}<0.05)$, while there was no statistical significance compared with the after modeling $(\mathrm{p}<0.05)$. On the 3rd day of the experiment, the Gln group of plasma and intestinal mucosal level of IL-1 and TNF- $\alpha$ level was significantly higher than before $(\mathrm{p}<0.05)$. Compared with the after modeling and control group, on the 7th day of experiment, the Gln group of plasma and intestinal mucosal IL-1, and TNF- $\alpha$ levels were significantly decreased $(\mathrm{p}<0.05)$. There was no statistical significance compared with other data (Table III). 
Table I. Expression of HMGB1 protein was examined in rat intestinal mucosal.

\begin{tabular}{lccccccrr}
\hline Group & $\mathrm{n}$ & Before modeling & After modeling & 3rd day & 7th day & P1 & P2 & P3 \\
\hline Control & 24 & $0.13 \pm 0.01$ & $0.93 \pm 0.08$ & $0.79 \pm 0.05$ & $0.85 \pm 0.06$ & 0.034 & 0.026 & 0.035 \\
Gln & 24 & $0.13 \pm 0.01$ & $0.87 \pm 0.07$ & $0.72 \pm 0.04$ & $0.58 \pm 0.03^{\mathrm{a}, \mathrm{b}}$ & 0.023 & 0.032 & 0.029 \\
\hline
\end{tabular}

P1, before building compared with after building; P2, the 3rd day compared with before building; P3, before building compared with the 7th day; ${ }^{\mathrm{P}} \mathrm{P}$, Gln group compared with after molding on the 7th day; ${ }^{\mathrm{P}} \mathrm{P}$, Gln group compared with the control group on the 7th day; HMGB1, high mobility group box 1; Gln, glutamine.

Table II. Expression of NF- $\mathrm{BB}$ were examined by immunohistochemitry in rat intestinal mucosal [n (\%)].

\begin{tabular}{lcccccrrr}
\hline Group & $\mathrm{n}$ & Before modeling & After modeling & 3rd day & 7th day & P1 & P2 & P3 \\
\hline Control & 24 & $2(8.3)$ & $18(75.0)$ & $16(66.7)$ & $15(62.5)$ & 0.013 & 0.027 & 0.002 \\
Gln & 24 & $2(8.3)$ & $17(70.8)$ & $14(58.3)$ & $9(37.5)^{\mathrm{a}, \mathrm{b}}$ & 0.019 & 0.038 & 0.032 \\
\hline
\end{tabular}

P1, before building compared with after building; P2, the 3rd day compared with before building; P3, before building compared with the 7th day; ${ }^{\mathrm{P}} \mathrm{P}$, Gln group compared with after molding on the 7 th day; ${ }^{\mathrm{b}} \mathrm{P}$, Gln group compared with the control group on the 7 th day. NF- $\mathrm{B}$, nuclear factor- $\kappa \mathrm{B} ;$ Gln, glutamine.

Table III. Levels of TNF- $\alpha$ and IL-1 in rat plasma and intestinal mucosa.

\begin{tabular}{|c|c|c|c|c|c|}
\hline \multirow[b]{2}{*}{ Group } & \multirow[b]{2}{*}{$\mathrm{n}$} & \multicolumn{2}{|c|}{ Plasma (ng/l) } & \multicolumn{2}{|c|}{ Intestinal mucosa $(\mathrm{pg} / \mathrm{g})$} \\
\hline & & $\mathrm{TNF}-\alpha$ & IL-1 & TNF- $\alpha$ & IL-1 \\
\hline Control & 24 & & & & \\
\hline Before modeling & 6 & $85.18 \pm 8.84$ & $112.75 \pm 17.48$ & $172.45 \pm 33.76$ & $230.15 \pm 55.74$ \\
\hline After modeling & 6 & $127.62 \pm 14.24^{\mathrm{a}}$ & $148.55 \pm 21.56^{\mathrm{a}}$ & $241.28 \pm 65.29^{a}$ & $315.86 \pm 74.36^{\mathrm{a}}$ \\
\hline The 3rd day & 6 & $121.75 \pm 13.72^{\mathrm{a}}$ & $140.79 \pm 18.36^{\mathrm{a}}$ & $226.23 \pm 55.35^{\mathrm{a}}$ & $301.24 \pm 69.45^{\mathrm{a}}$ \\
\hline The 7 th day & 6 & $113.83 \pm 11.69^{\mathrm{a}}$ & $141.78 \pm 20.65^{\mathrm{a}}$ & $214.76 \pm 54.82^{\mathrm{a}}$ & $298.37 \pm 65.33^{\mathrm{a}}$ \\
\hline $\mathrm{P} 1$ & & 0.018 & 0.027 & 0.036 & 0.031 \\
\hline $\mathrm{P} 2$ & & 0.025 & 0.021 & 0.042 & 0.028 \\
\hline P3 & & 0.041 & 0.029 & 0.038 & 0.022 \\
\hline Gln group & 24 & & & & \\
\hline Before modeling & 6 & $85.18 \pm 8.84$ & $113.82 \pm 17.28$ & $172.45 \pm 33.76$ & $230.39 \pm 54.66$ \\
\hline After modeling & 6 & $123.86 \pm 13.75^{\mathrm{a}}$ & $145.76 \pm 21.38^{\mathrm{a}}$ & $240.35 \pm 64.86^{\mathrm{a}}$ & $317.48 \pm 70.64^{\mathrm{a}}$ \\
\hline The 3rd day & 6 & $117.35 \pm 11.29^{\mathrm{a}}$ & $138.22 \pm 17.38^{\mathrm{a}}$ & $213.78 \pm 43.76^{\mathrm{a}}$ & $301.65 \pm 64.57^{\mathrm{a}}$ \\
\hline The 7 th day & 6 & $92.76 \pm 9.42^{\mathrm{b}}$ & $131.65 \pm 14.57^{\mathrm{b}}$ & $184.53 \pm 42.16^{\mathrm{b}}$ & $237.26 \pm 56.81^{\mathrm{b}}$ \\
\hline $\mathrm{P} 1$ & & 0.035 & 0.027 & 0.011 & 0.031 \\
\hline $\mathrm{P} 2$ & & 0.036 & 0.039 & 0.032 & 0.030 \\
\hline $\mathrm{P} 4$ & & 0.032 & 0.031 & 0.026 & 0.017 \\
\hline P5 & & 0.025 & 0.028 & 0.039 & 0.022 \\
\hline
\end{tabular}

Data are presented as mean $\pm \mathrm{SD}$. ${ }^{\mathrm{a}} \mathrm{P}<0.05$ vs. before modeling, ${ }^{\mathrm{b}} \mathrm{p}<0.05$ vs. control group, day 7 . TNF- $\alpha$, tumor necrosis factor- $\alpha$; IL-1, interleukin-1; Gln, glutamine.

Levels of Gln, D-lactic acid and DAO in rat plasma. Compared with before modeling, the two groups after modeling of rats plasma D-lactic acid and DAO levels were increased significantly $(\mathrm{p}<0.05)$, while the plasma level of Gln was decreased. On the 3rd day and the 7th day of the experiment, the control group rats plasma D-lactic acid and DAO levels were significantly higher than the before modeling, while the plasma level of Gln below the before modeling was increased significantly $(\mathrm{p}<0.05)$. There was no statistical significance compared with other data (Table IV). 
Table IV. Levels of Gln, D-lactic acid and DAO in rat plasma.

\begin{tabular}{|c|c|c|c|c|}
\hline Group & $\mathrm{n}$ & D-lactic acid (mmol/l) & $\mathrm{DAO}(\mathrm{U} / \mathrm{ml})$ & $\mathrm{Gln}(\mathrm{g} / \mathrm{l})$ \\
\hline Control & 24 & & & \\
\hline Before modeling & 6 & $0.27 \pm 0.02$ & $1.52 \pm 0.24$ & $0.39 \pm 0.03$ \\
\hline After modeling & 6 & $0.46 \pm 0.03^{\mathrm{a}}$ & $2.76 \pm 0.57^{\mathrm{a}}$ & $0.18 \pm 0.01^{\mathrm{a}}$ \\
\hline The 3rd day & 6 & $0.41 \pm 0.03^{\mathrm{a}}$ & $2.51 \pm 0.52^{\mathrm{a}}$ & $0.22 \pm 0.01^{\mathrm{a}}$ \\
\hline The 7th day & 6 & $0.53 \pm 0.05^{\mathrm{a}}$ & $2.47 \pm 0.55^{\mathrm{a}}$ & $0.21 \pm 0.03^{\mathrm{a}}$ \\
\hline $\mathrm{P} 1$ & & 0.041 & 0.015 & 0.026 \\
\hline $\mathrm{P} 2$ & & 0.029 & 0.034 & 0.042 \\
\hline P3 & & 0.030 & 0.016 & 0.035 \\
\hline Gln group & 24 & & & \\
\hline Before modeling & 6 & $0.27 \pm 0.02$ & $1.52 \pm 0.24$ & $0.39 \pm 0.03$ \\
\hline After modeling & 6 & $0.51 \pm 0.04^{\mathrm{a}}$ & $2.58 \pm 0.51^{\mathrm{a}}$ & $0.21 \pm 0.01^{\mathrm{a}}$ \\
\hline The 3rd day & 6 & $0.45 \pm 0.03^{\mathrm{a}}$ & $2.26 \pm 0.43^{\mathrm{a}}$ & $0.32 \pm 0.02^{\mathrm{b}}$ \\
\hline The 7th day & 6 & $0.31 \pm 0.02^{b}$ & $1.76 \pm 0.34^{\mathrm{b}}$ & $0.40 \pm 0.03^{\mathrm{b}}$ \\
\hline $\mathrm{P} 1$ & & 0.018 & 0.037 & 0.031 \\
\hline $\mathrm{P} 2$ & & 0.032 & 0.025 & 0.032 \\
\hline $\mathrm{P} 4$ & & 0.024 & 0.022 & 0.028 \\
\hline P5 & & 0.037 & 0.036 & 0.032 \\
\hline
\end{tabular}

Data are presented as mean $\pm \mathrm{SD}$. ${ }^{\mathrm{a}} \mathrm{P}<0.05$ vs. before modeling, ${ }^{\mathrm{b}} \mathrm{p}<0.05$ vs. control group, day 7 . Gln, glutamine; DAO, diamine oxidase.
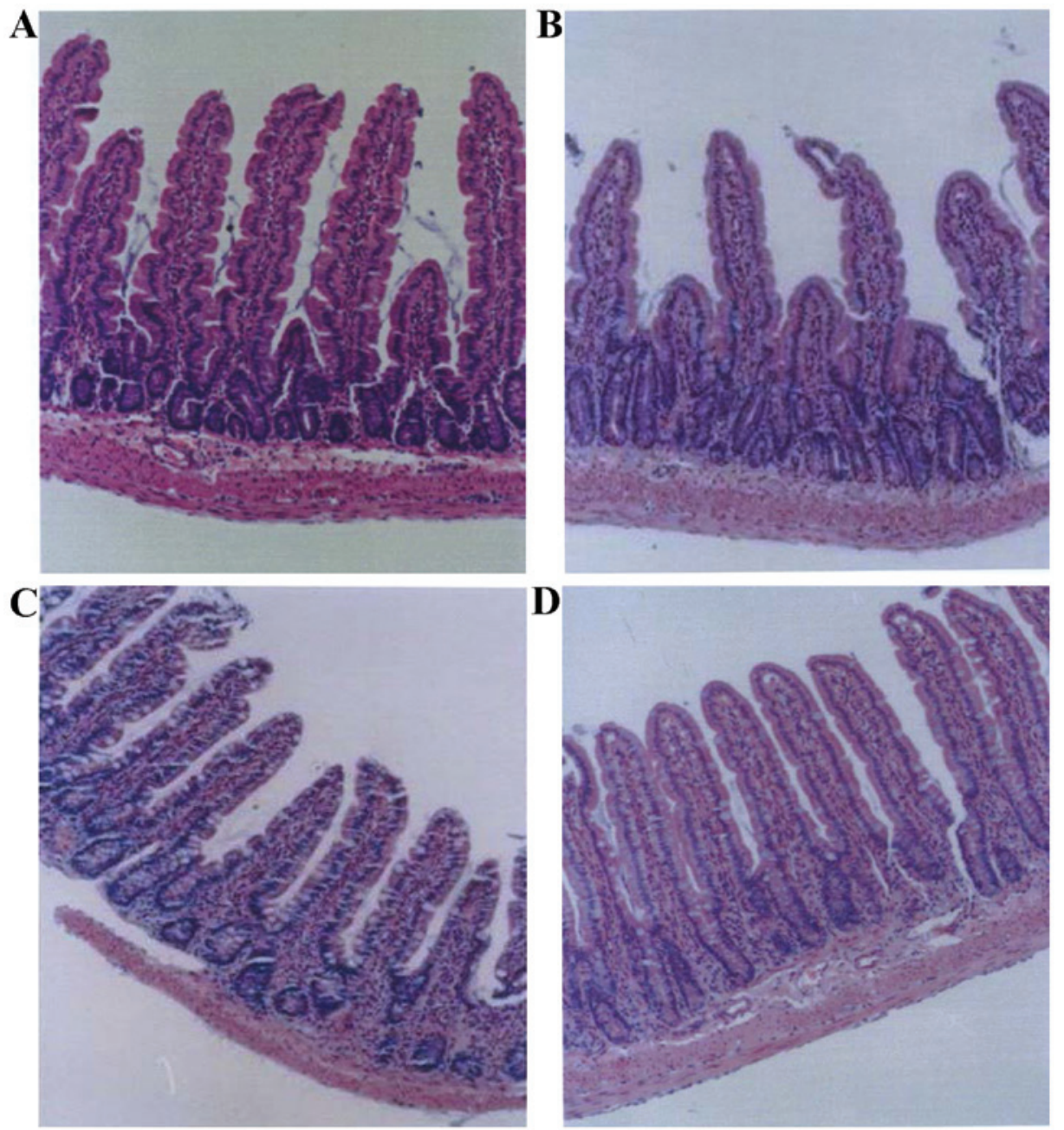

Figure 1. Changes in morphology of rat intestinal mucosa. Basal morphology prior to IR (A), basal morphology after IR (B), day 7 in control group (C), and day 7 in Gln group (D). Hematoxylin and eosin staining (magnification, x100). IR, ischemia-reperfusion. 
Morphology of small intestinal mucosa. Basal small intestinal mucosa and crypt structure was normal, with no obvious infiltration of inflammatory cells in the lamina propria (Fig. 1A). However, IR led to damage to the villi and crypt structure, and shorter, thinner hairs (Fig. 1B). Furthermore, the lamina propria exhibited a large number of invading inflammatory cells, lymphangiectasia and edema (Fig. 1B). On day 7 after IR, the animals treated with Gln showed a marked recovery of the structure of the intestine structure and crypts, such that they became comparable to the small intestinal mucosa at basal condition, and lamina propria had a small amount of invading inflammatory cells (Fig. 1C). However, the control group showed substantial morphological changes and marked inflammatory cell infiltration on day 7 (Fig. 1D).

\section{Discussion}

Visceral blood flow reduction following surgical trauma or shock is a common clinical phenomenon (8). It causes intestinal IR injury and activates neutrophils to release inflammatory cytokines and free radicals which cause tissue damage and affect intestinal mucosal permeability (9). Gln is the main energy material for intestinal mucosal rapidly dividing cells. During IR, deficiency of Gln can occur (10). In the present study, we demonstrate that animal IR is associated with lower levels of plasma Gln and the upregulation of inflammatory. However, supplementation with Gln led to increased recovery.

Gln is an important precursor of adenosine triphosphate and adenosine monophosphate which are used to power the intestinal mucosal cell metabolic oxidation $(11,12)$. Furthermore, Gln is the precursor to glutathione, an important antioxidant that protects intestinal epithelial cells from oxidant damage and inhibits intestinal mucosal apoptosis $(13,14)$. Gln can modulate inflammatory responses $(15,16)$. Additionally, Gln increases the cell oxygen uptake rate, enterocyte mitochondrial respiratory function, and improves the intestinal blood supply (17).

HMGB1 is a nucleoprotein present in almost all eukaryotic nuclei and involved in the regulation of inflammatory responses (18). When cells are stimulated with microbial pathogens or inflammatory factors, intracellular HMGB1 can be released into the extracellular compartment to stimulate immune responses (19). This stimulation increases intestinal mucosa monolayer permeability, facilitates bacterial translocation, and allows the endotoxin from the gut lumen to reach inside the body. We have demonstrated that Gln supplementation decreases the expression of HMGB1 in the rat intestinal mucosa.

The same beneficial effect of Gln supplementation was observed with respect to $\mathrm{NF}-\kappa \mathrm{B}$. This transcription factor is crucial for inciting and prolonging the inflammatory response (20). Activation of this transcription factor leads to upregulation of the production of inflammatory cytokines, such as TNF- $\alpha$ and IL-1, which were investigated in the present study. Downregulation of NF- $\kappa \mathrm{B}$ expression by Gln supplementation, as observed in the present results, may be associated with reduced degradation of $\mathrm{I} \kappa \mathrm{B}$, as demonstrated in Gln-supplemented cells (21). I $\mathrm{B}$ normally prevents $\mathrm{NF}-\kappa \mathrm{B}$ from activation, thus, Gln beneficially modulated $N F-\kappa B$ in the present study.
Supporting the involvement of $\mathrm{NF}-\kappa \mathrm{B}$ in anti-inflammatory effects of Gln supplementation, TNF- $\alpha$ and IL-1, initially upregulated by IR injury, were downregulated in Gln-supplemented animals. Similar studies in the literature have shown that, Gln exerts a protective effect on the barrier function of intestinal mucosa during inflammatory insults (22). This can decrease exposure to gut microflora or their virulence factors.

We also studied the kinetics of plasma D-lactate and DAO levels as markers of intestinal membrane injury $(23,10)$. Notably, plasma D-lactate levels have been found to reflect the permeability and barrier function of intestinal mucosa (24), whereas plasma DAO levels are associated with intestinal mucosal epithelial cell injury and repair $(25,26)$. We observed that GIn supplementation markedly decreased the levels of the aforementioned markers.

These beneficial changes in Gln-supplemented animals were documented at day 7 after induction of the IR injury and were supported by less pronounced morphological changes of the intestinal mucosa. This is likely to indicate that inflammatory responses during IR strongly contribute to the damage to the intestinal mucosa, and that reducing the inflammatory response, as in the case of Gln-supplemented animals, is a prerequisite to preventing this damage to the intestinal mucosa.

Since the aforementioned beneficial changes of Gln supplementation occurred after 7 days post-IR injury, we believe that Gln facilitates cell recovery from the injury. In conclusion, we have demonstrated that Gln supplementation exerts beneficial anti-inflammatory effects in a rat model of IR injury and reduces morphological changes in the intestinal mucosa after this injury. This provides experimental evidence for the utilization of Gln supplementation to facilitate recovery of patients with intestinal IR injury.

\section{Acknowledgements}

The present study was supported by the Key Specialty Construction Project of the Pudong Health and Family Planning Commission of Shanghai (grant no. PWZz2013-17).

\section{References}

1. Mura M, Andrade CF, Han B, Seth R, Zhang Y, Bai XH, Waddell TK, Hwang D, Keshavjee S and Liu M: Intestinal ischemia-reperfusion-induced acute lung injury and oncotic cell death in multiple organs. Shock 28: 227-238, 2007.

2. He GZ, Dong LG, Chen XF, Zhou KG and Shu H: Lymph duct ligation during ischemia/reperfusion prevents pulmonary dysfunction in a rat model with $\omega-3$ polyunsaturated fatty acid and glutamine. Nutrition 27: 604-614, 2011.

3. Collange O, Tamion F, Chanel S, Hue G, Richard V, Thuilliez C, Dureuil B and Plissonnier D: D-lactate is not a reliable marker of gut ischemia-reperfusion in a rat model of supraceliac aortic clamping. Crit Care Med 34: 1415-1419, 2006.

4. Wischmeyer PE: Glutamine: role in gut protection in critical illness. Curr Opin Clin Nutr Metab Care 9: 607-612, 2006.

5. Songsasen N, Wesselowski S, Carpenter JW and Wildt DE: The ability to achieve meiotic maturation in the dog oocyte is linked to glycolysis and glutamine oxidation. Mol Reprod Dev 79: 186-196, 2012

6. Barnes JL, Hartmann B, Holst JJ and Tappenden KA: Intestinal adaptation is stimulated by partial enteral nutrition supplemented with the prebiotic short-chain fructooligosaccharide in a neonatal intestinal failure piglet model. JPEN J Parenter Enteral Nutr 36: 524-537, 2012. 
7. Padda RS, Gkouvatsos K, Guido M, Mui J, Vali H and Pantopoulos K: A high-fat diet modulates iron metabolism but does not promote liver fibrosis in hemochromatotic $\mathrm{Hjv}^{-/ 2}$ mice. Am J Physiol Gastrointest Liver Physiol 308: G251-G261, 2015.

8. Wen AD, Jiang YP and Fan YX: Using HPLC fluorescence method for rapid detection of glutamine in human plasma and muscle. Chromatography, pp406-407, 1995.

9. Kim KH, Kuh SU, Park JY, Kim KS, Chin DK and Cho YE: What is the importance of 'halo' phenomenon around bone cement following vertebral augmentation for osteoporotic compression fracture? Osteoporos Int 23: 2559-2565, 2012.

10. Tian R, Tan JT, Wang RL, Xie H, Qian YB and Yu KL: The role of intestinal mucosa oxidative stress in gut barrier dysfunction of severe acute pancreatitis. Eur Rev Med Pharmacol Sci 17: 349-355, 2013

11. Chen X, Guan T, Li C, Shang H, Cui L, Li XM and Kong J: SOD1 aggregation in astrocytes following ischemia/reperfusion injury: a role of NO-mediated S-nitrosylation of protein disulfide isomerase (PDI). J Neuroinflammation 9: 237, 2012.

12. Alves MA, Guimarães SB, Dias DA, Vasconcelos PR, Coelho VP and Vasconcelos PR: Effects of L-alanyl-glutamine upon the blood and kidney biochemical parameters in the rat hind limb model of ischemia/reperfusion. Acta Cir Bras 20: 445-449, 2005

13. De-Souza DA and Greene LJ: Intestinal permeability and systemic infections in critically ill patients: effect of glutamine. Crit Care Med 33: 1125-1135, 2005.

14. Sözen S, Topuz O, Uzun AS, Cetinkünar S and Das K: Prevention of bacterial translocation using glutamine and melatonin in small bowel ischemia and reperfusion in rats. Ann Ital Chir 83: $143-148,2012$

15. Deniel N, Marion-Letellier R, Charlionet R, Tron F, Leprince J, Vaudry H, Ducrotté P, Déchelotte P and Thébault S: Glutamine regulates the human epithelial intestinal HCT-8 cell proteome under apoptotic conditions. Mol Cell Proteomics 6: 1671-1679, 2007.

16. Yeh SL, Lai YN, Shang HF, Lin MT, Chiu WC and Chen WJ: Effects of glutamine supplementation on splenocyte cytokine mRNA expression in rats with septic peritonitis. World J Gastroenterol 11: 1742-1746, 2005.

17. Kessel A, Toubi E, Pavlotzky E, Mogilner J, Coran AG, Lurie M, Karry R and Sukhotnik I: Treatment with glutamine is associated with down-regulation of Toll-like receptor-4 and myeloid differentiation factor 88 expression and decrease in intestinal mucosal injury caused by lipopolysaccharide endotoxaemia in a rat. Clin Exp Immunol 151: 341-347, 2008.
18. Filipp FV, Ratnikov B, De Ingeniis J, Smith JW, Osterman AL and Scott DA: Glutamine-fueled mitochondrial metabolism is decoupled from glycolysis in melanoma. Pigment Cell Melanoma Res 25: 732-739, 2012.

19. Naruse K, Sado T, Noguchi T, Tsunemi T, Yoshida S, Akasaka J, Koike N, Oi H and Kobayashi H: Peripheral RAGE (receptor for advanced glycation endproducts)-ligands in normal pregnancy and preeclampsia: novel markers of inflammatory response. J Reprod Immunol 93: 69-74, 2012.

20. Hedl M and Abraham C: Nod2-induced autocrine interleukin-1 alters signaling by ERK and p38 to differentially regulate secretion of inflammatory cytokines. Gastroenterology 143: 1530-1543, 2012

21. Kang J, Tae N, Min BS, Choe J and Lee JH: Malabaricone C suppresses lipopolysaccharide-induced inflammatory responses via inhibiting ROS-mediated Akt/IKK/NF- $\kappa \mathrm{B}$ signaling in murine macrophages. Int Immunopharmacol 14: 302-310, 2012

22. Karatepe O, Acet E, Battal M, Adas G, Kemik A, Altiok M, Kamali G, Koculu S, Catay A, Kamali S, et al: Effects of glutamine and curcumin on bacterial translocation in jaundiced rats. World J Gastroenterol 16: 4313-4320, 2010.

23. Websky M, Fujishiro J, Ohsawa I, Praktiknjo M, Wehner S, Abu-Elmagd K, Kitamura K, Kalff JC, Schaefer N and Pech T: The novel guanylhydrazone CPSI-2364 ameliorates ischemia reperfusion injury after experimental small bowel transplantation. Transplantation 95: 1315-1323, 2013.

24. Pan ZY, Long CL and Wang H: Functional and morphological structure changes in the gut barrier during cholinesterase inhibitor intoxication and therapeutic effect of benthiactzine in rats. Zhongguo Wei Zhong Bing Ji Jiu Yi Xue 22: 197-200, 2010 (In Chinese).

25. Cai C, Li W, Chen J, Li X and Chen S: Diamine oxidase as a marker for diagnosis of superior mesenteric arterial occlusion. Hepatogastroenterology 59: 155-158, 2012.

26. Santos RG, Quirino IE, Viana ML, Generoso SV, Nicoli JR, Martins FS, Nogueira-Machado JA, Arantes RM, Correia MI and Cardoso VN: Effects of nitric oxide synthase inhibition on glutamine action in a bacterial translocation model. Br J Nutr 111: 93-100, 2014. 